\title{
How patients fare after anaesthesia for elective surgery: a survey of postoperative nausea and vomiting, pain and confusion
}

Yun Zhi Lee $\underline{L}^{1}$ MBBS, Ruth Qianyi $\underline{\operatorname{Lee}}^{1}$, MBBS, Kyu Kyu $\underline{T h i n n^{2}}$, MBBS, Keah How $\underline{\text { Poon }}^{1}$, MBBS, MMed, Eugene Hern Choon $\underline{L i u}^{2}$, MD, FRCA

\begin{abstract}
INTRODUCTION Postoperative nausea and vomiting (PONV), and postoperative pain are common during the early postoperative period. In addition to these problems, elderly patients risk developing postoperative confusion. This study aimed to identify the risk factors associated with these problems, and the extent of these problems, in a Singapore inpatient surgical population.

METHODS Over a period of six weeks, we surveyed 707 elective surgical inpatients aged $\geq 18$ years who received general anaesthesia and/or regional anaesthesia.

RESULTS The incidence of PONV was 31.8\% (95\% confidence interval [Cl] 34.8-41.9). The incidence increased with increasing Apfel score $(p<0.001)$ and were higher in female patients (odds ratio [OR] 1.74, 95\% Cl 1.28-2.36), nonsmokers (OR 1.72, 95\% Cl 1.04-2.88), patients with a history of PONV and/or motion sickness (OR 3.45, 95\% Cl 2.38-5.24), patients who received opioids (OR 1.39, 95\% Cl 1.03-1.88), and patients who received general anaesthesia (OR 1.76 , 95\% $\mathrm{Cl} 1.11-2.79$ ). Moderate to severe pain at rest and with movement were reported in $19.9 \%$ and $52.5 \%$ of patients, respectively. Among the patients who were predicted to experience mild pain, $29.5 \%$ reported moderate pain and $8.1 \%$ reported severe pain. The prevalence of postoperative confusion was $3.9 \%$ in the geriatric population.

CONCLUSION Higher Apfel scores were associated with a higher risk of PONV and multimodal treatment for postoperative pain management was found to be insufficient. The incidence of postoperative confusion was low in this study.
\end{abstract}

Keywords: postoperative confusion, postoperative delirium, postoperative nausea and vomiting, postoperative pain, postoperative sore throat

\section{INTRODUCTION}

Postoperative nausea and vomiting (PONV), and postoperative pain are among the most common problems encountered during the early postoperative period. Recent studies report that the incidence of PONV ranges from $9 \%$ to $56 \%$, while a metaanalysis of these studies found that the overall occurrence of PONV was $28.3 \% .{ }^{(1)}$ Similarly, a systematic review of published data on postoperative pain management found that $29.7 \%$ of patients reported moderate to severe pain at some point during the 24-hour period after surgery. ${ }^{(2)}$

Patients have ranked vomiting and incisional pain as the top fears that they have after anaesthesia and surgery. ${ }^{(3)}$ Other than that, postoperative pain and its management have been shown to affect the risk of developing postoperative delirium in elderly patients. ${ }^{(4,5)}$ Therefore, in the present study, we evaluated the risk factors for these problems, as well as the extent of these postoperative problems, in a Singapore inpatient surgical population.

\section{METHODS}

A survey of postoperative outcomes was conducted over a six-week period at a tertiary institution in Singapore. All elective surgical inpatients aged $\geq 18$ years who received general anaesthesia and/or regional anaesthesia were eligible for inclusion in the present study. The exclusion criteria were as follows: (a) underwent monitored anaesthetic care without general or regional anaesthesia; (b) admitted to the intensive care unit, neurosurgery high-dependency unit or the psychiatric ward in the immediate postoperative period; (c) had cognitive impairment; (d) had difficulty with verbal communication; and (e) spoke languages other than English, Mandarin, Chinese dialects or Malay. The Domain Specific Review Board of the National Healthcare Group was informed and consulted about the department's audit, and such quality improvement work was exempted from formal review. We obtained verbal consent from each patient prior to the start of the interview.

Two interviewers administered a standardised survey questionnaire (see Annex) to eligible patients, approximately 24 hours after the patient's surgery. Chinese- and Malay-language questionnaires were forward and backward translated beforehand to ensure accuracy. Patients who spoke Chinese dialects or Malay were interviewed through a translator, who was either their relative or a nursing staff in the ward. Patients were asked about the presence of nausea (i.e. the sensation of wanting to vomit) and the intensity of the nausea experienced (i.e. mild, moderate or severe). The number of episodes of vomiting was also recorded. Patients' smoking status and history of PONV and/ or motion sickness, if any, were noted. We computed the Apfel risk score ${ }^{(6)}$ for PONV. The Apfel score ranged from 0 to 4 , and was calculated by scoring 1 for the presence of each of these four

${ }^{1}$ Department of Anaesthesia, National University Hospital, National University Health System, ${ }^{2}$ Department of Anaesthesia, Yong Loo Lin School of Medicine, National University of Singapore, National University Health System, Singapore

Correspondence: A/Prof Eugene Liu, Head and Senior Consultant, Department of Anaesthesia, National University Hospital, 5 Lower Kent Ridge Road, Singapore 119074. Eugene_Liu_HC@nuhs.edu.sg 
risk factors: female gender, nonsmoker, history of PONV and/or motion sickness, and postoperative opioid use.

The severity of postoperative pain was assessed during the interview using a descriptive verbal rating scale (i.e. no pain, mild, moderate or severe pain). Such a scale was used because it is easy to administer in different languages and can be easily understood by patients. Five different pain scores for operative site pain were recorded: (a) pain at rest 24 hours after surgery; (b) pain during movement 24 hours after surgery; (c) highest pain score over the last 24 hours since surgery; (d) lowest pain score over the last 24 hours since surgery; and (e) average pain score over the last 24 hours since surgery. 'Pain at rest' refers to pain experienced when the patient is in bed without movement, while 'pain during movement' refers to dynamic pain (e.g. pain when sitting up, pain when turning in bed, pain when getting out of bed, pain during deep breathing, and pain when coughing or straining). The incidence of postoperative sore throat was also recorded.

The data on postoperative pain was evaluated according to the type of surgery the patients underwent and the anticipated level of postoperative pain. The anticipated levels of postoperative pain were decided based on reported data and our clinical experience. (7) Mild pain was anticipated for minor head and neck, minor limb, minor urological and minor lower abdominal surgeries (e.g. thyroidectomy, eye surgery, limb vascular surgery, arthroscopy, endoscopic urological procedures, hernia, cervix and vaginal surgery, and wound debridement). Moderate pain was anticipated for major head and neck, intermediate limb, minor thoracic and breast, minor upper abdominal, intermediate lower abdominal and minor spinal surgeries (e.g. oral and throat surgery, limb fracture open reduction and internal fixation, discectomy, mastectomy, cholecystectomy, appendectomy, lower segment Caesarean section and hysterectomy). Severe pain was anticipated for major limb, major thoracic, major upper and lower abdominal and major spinal surgeries (e.g. shoulder reconstruction surgery, lobectomy, colectomy, hepatectomy, gastrectomy, hip or knee replacement and spinal fusion surgery).

The patients' premorbid neurological status and mental state were also recorded. We used the Confusion Assessment Method for the intensive care unit (CAM-ICU) $)^{(8)}$ to assess postoperative confusion. To determine the presence or absence of emergence delirium, postanaesthesia care unit (PACU) clinical charts were reviewed. If the term 'restless', 'agitated', 'confused' or 'delirious' were documented by the PACU anaesthetist, the patient was taken to have emergence delirium. Data on the antiemetics and analgesia prescribed and administered were obtained from the intraoperative anaesthetic chart and the electronic inpatient medical record system.

Statistical analysis was performed using IBM SPSS Statistics software version 20.0 (IBM Corp, Armonk, NY, USA). Confidence intervals were obtained with calculators for the Newcombe score using the Wilson procedure with correction for continuity. Chi-square tests were used to determine statistical significance. Chi-square test for trend was used to evaluate the relationship of PONV and Apfel score. Univariate analysis was used to explore the risk factors that were thought to contribute to PONV (e.g. Apfel
Table I. Profile of the patients $(n=707)$.

\begin{tabular}{|c|c|}
\hline Variable & No. (\%) \\
\hline \multicolumn{2}{|l|}{ Age group (yr) } \\
\hline $18-40$ & $229(32.4)$ \\
\hline $41-64$ & $306(43.3)$ \\
\hline $65-79$ & $139(19.7)$ \\
\hline$\geq 80$ & $33(4.7)$ \\
\hline \multicolumn{2}{|l|}{ Gender } \\
\hline Female & $371(52.5)$ \\
\hline Male & $336(47.5)$ \\
\hline \multicolumn{2}{|l|}{ Ethnicity } \\
\hline Chinese & $447(63.2)$ \\
\hline Indian & $82(11.6)$ \\
\hline Malay & $120(17.0)$ \\
\hline Others & $58(8.2)$ \\
\hline \multicolumn{2}{|l|}{ Surgical discipline } \\
\hline Orthopaedics, hand \& reconstructive microsurgery & $248(35.1)$ \\
\hline General surgery & $142(20.1)$ \\
\hline Obstetrics \& gynaecology & $124(17.5)$ \\
\hline Urology & $72(10.2)$ \\
\hline Others & $121(17.1)$ \\
\hline \multicolumn{2}{|l|}{ Type of anaesthesia } \\
\hline General anaesthesia only & $537(76.0)$ \\
\hline Regional anaesthesia only & $108(15.3)$ \\
\hline General and regional anaesthesia & $62(8.8)$ \\
\hline \multicolumn{2}{|l|}{ Type of regional anaesthesia } \\
\hline \multicolumn{2}{|l|}{ Central nerve block } \\
\hline Spinal & $88(12.4)$ \\
\hline Epidural & $5(0.7)$ \\
\hline Combined spinal epidural & $7(1.0)$ \\
\hline \multicolumn{2}{|l|}{ Peripheral nerve block } \\
\hline Brachial plexus & $9(1.3)$ \\
\hline Ilioinguinal & $8(1.1)$ \\
\hline Femoral & $39(5.5)$ \\
\hline Others & $14(2.0)$ \\
\hline \multicolumn{2}{|l|}{ Smoking status* } \\
\hline Smoker & $91(18.1)$ \\
\hline Nonsmoker & $411(81.9)$ \\
\hline \multicolumn{2}{|l|}{ History of PONV/motion sickness* } \\
\hline Yes & $142(28.3)$ \\
\hline No & $360(71.7)$ \\
\hline
\end{tabular}

*Data on smoking status and history of PONV/motion sickness were only available for 502 patients. PONV: postoperative nausea and vomiting

factors, type of anaesthesia, use of total intravenous anaesthesia [TIVA], use of nitrous oxide and age).

\section{RESULTS}

Although 727 patients were eligible for inclusion in the present study, 20 patients were excluded due to various reasons 10 patients were excluded because a questionnaire in their language was not available, 5 patients refused participation and 5 were not present in their rooms despite three attempts to reach them. Among the 10 patients who were excluded because a questionnaire in their language was not available, 3 were of Indian ethnicity and 7 were of ethnicities other than Chinese, Malay or Indian.

A total of 707 patients were included in the present study; their profiles are presented in Table I. There were similar proportions of male and female patients, and the three major ethnic groups in Singapore were represented. 
The incidences of postoperative nausea and postoperative vomiting were $31.8 \%$ (95\% confidence interval [Cl] 28.4-35.3) and $24.6 \%$ (95\% Cl 21.4-27.8), respectively. Among the patients, 18.0\% (95\% Cl 15.1-20.8) experienced both nausea and vomiting, and the overall incidence of PONV, defined as nausea and/or vomiting experienced in the first 24 hours after surgery, was $38.3 \%$ (95\% Cl 34.8-41.9). The severity of nausea and the number of vomiting episodes are shown in Table II. Within the first 24 hours after surgery, $2.3 \%$ of patients vomited seven times or more. The rates of PONV were strongly related to the patients' Apfel scores $(p<0.001)$, ranging from $17.6 \%$ for those with a score of 0 to $58.6 \%$ for those with a score of 4 (Table III).

The impact of the risk factors on PONV is shown in Table IV. Female patients, nonsmokers, patients with a previous history of PONV/motion sickness and patients who received opioids postoperatively had a higher risk of PONV. Patients who received general anaesthesia had a higher risk of PONV compared to those who received regional anaesthesia. Intraoperative use of propofol for TIVA and intraoperative use of nitrous oxide were not found to affect the risk of PONV in the present study. However, the number of the patients who had propofol TIVA $(n=35)$ and number of the patients who had nitrous oxide anaesthesia $(n=11)$ were very small.

The prevalence of the severity of the postoperative pain experienced by the patients is summarised in Table V. Most of the patients $(66.7 \%)$ experienced moderate or severe pain at some point during the first 24 hours after surgery. Some patients $(22.8 \%)$ reported having either moderate or severe pain throughout the 24 -hour period after surgery and $4.1 \%$ of patients reported experiencing severe pain throughout. At approximately 24 hours after surgery, $19.9 \%$ of the patients still had at least moderate pain at rest and $52.5 \%$ still had at least moderate pain on movement; $2.5 \%$ of the patients had severe pain at rest and $16.1 \%$ had severe pain on movement.

Table VI shows the average pain experienced by the patients within 24 hours after surgery, according to the different types of surgery and the anticipated postoperative pain level. Among the patients who were anticipated to experience mild pain, 29.5\% of them reported moderate pain and $8.1 \%$ reported severe pain on average.

The analgesic prescriptions and administration for the different types of surgery are shown in Table VII. The majority of the patients $(98.6 \%)$ were prescribed postoperative analgesics. The most commonly prescribed and administered analgesic was paracetamol, followed by nonsteroidal anti-inflammatory drugs/selective COX-2 inhibitors (NSAIDs/coxibs) and tramadol. Opioids were prescribed for $37.1 \%$ of the patients who were anticipated to have moderate pain and for $85.9 \%$ of the patients who were anticipated to have severe pain. Prescriptions of paracetamol, NSAIDs/coxibs and tramadol were adhered to $91.0 \%$ of the time, whereas prescriptions for subcutaneous, intramuscular and oral opioids were adhered to only $45.7 \%$ of the time. Among the patients who had patient-controlled analgesia (PCA) with morphine, $50.0 \%$ and $12.3 \%$ reported moderate and severe pain on average, respectively, within the 24 hours after surgery.
Table II. Proportion of patients with nausea and vomiting within the first 24 hours after anaesthesia and surgery $(n=707)$.

\begin{tabular}{lc}
\hline Parameter & No. (\%) \\
\hline Nausea & \\
None & $482(68.2)$ \\
Mild & $98(13.9)$ \\
Moderate & $90(12.7)$ \\
Severe & $37(5.2)$ \\
Vomiting & \\
None & $533(75.4)$ \\
$1-3$ episodes & $131(18.5)$ \\
$4-6$ episodes & $27(3.8)$ \\
$\geq 7$ episodes & $16(2.3)$ \\
\hline
\end{tabular}

Table III. Proportion of patients with postoperative nausea and vomiting for each Apfel score.

\begin{tabular}{lr}
\hline Apfel score $(\mathbf{n}=\mathbf{5 0 2})^{*}$ & No. (\%) \\
\hline $0(n=34)$ & $6(17.6)$ \\
$1(n=139)$ & $35(25.2)$ \\
$2(n=180)$ & $56(31.1)$ \\
$3(n=120)$ & $62(51.7)$ \\
$4(n=29)$ & $17(58.6)$ \\
\hline
\end{tabular}

*Data for Apfel scores was only available for 502 patients.

Table IV. Results of the univariate analysis performed to determine the factors affecting postoperative nausea and vomiting (PONV).

\begin{tabular}{|c|c|}
\hline Factor & OR $(95 \% \mathrm{CI})$ \\
\hline \multicolumn{2}{|l|}{ Gender } \\
\hline Female & $1.74(1.28-2.36)$ \\
\hline Male & 1 \\
\hline \multicolumn{2}{|l|}{ Type of anaesthesia } \\
\hline General anaesthesia & $1.76(1.11-2.79)$ \\
\hline Regional anaesthesia & 1 \\
\hline \multicolumn{2}{|c|}{ Use of postoperative opioids } \\
\hline Yes & $1.39(1.03-1.88)$ \\
\hline No & 1 \\
\hline \multicolumn{2}{|l|}{ Smoking status } \\
\hline Nonsmoker & $1.72(1.04-2.88)$ \\
\hline Smoker & 1 \\
\hline \multicolumn{2}{|c|}{ History of PONV/motion sickness } \\
\hline Yes & $3.45(2.38-5.24)$ \\
\hline No & 1 \\
\hline \multicolumn{2}{|c|}{$\begin{array}{l}\text { Intraoperative use of propofol for } \\
\text { the maintenance of anaesthesia }\end{array}$} \\
\hline No & $0.81(0.42-1.56)$ \\
\hline Yes & 1 \\
\hline \multicolumn{2}{|c|}{ Intraoperative use of nitrous oxide } \\
\hline \multicolumn{2}{|c|}{ for the maintenance of anaesthesia } \\
\hline Yes & $0.90(0.26-3.09)$ \\
\hline No & 1 \\
\hline \multicolumn{2}{|l|}{ Age (yr) } \\
\hline $18-40$ & 1 \\
\hline $41-64$ & $0.89(0.62-1.26)$ \\
\hline $65-79$ & $0.77(0.50-1.19)$ \\
\hline$\geq 80$ & $0.53(0.24-1.19)$ \\
\hline
\end{tabular}

$\mathrm{Cl}$ : confidence interval; OR: odds ratio

Table VIII shows the incidence of postoperative sore throat. Overall, the incidence was $21.2 \%$. Patients who had tracheal intubation were found to have a higher risk of experiencing 
Table V. Prevalence of postoperative pain among the patients $(n=707)$.

\begin{tabular}{|c|c|c|c|c|}
\hline \multirow[t]{2}{*}{ Parameter } & \multicolumn{4}{|c|}{ Severity of pain } \\
\hline & None & Mild & Moderate & Severe \\
\hline \multicolumn{5}{|c|}{ Pain at $24 \mathrm{hr}$ after surgery } \\
\hline At rest & $211(29.8)$ & $355(50.2)$ & $123(17.4)$ & $18(2.5)$ \\
\hline On movement & 98 (13.9) & $238(33.7)$ & $257(36.4)$ & $114(16.1)$ \\
\hline \multicolumn{5}{|c|}{ Over the last $24 \mathrm{hr}$ since surgery } \\
\hline Highest pain score & $88(12.4)$ & 148 (20.9) & 197 (27.9) & $274(38.8)$ \\
\hline Lowest pain score & $182(25.7)$ & 364 (51.5) & $132(18.7)$ & $29(4.1)$ \\
\hline Average pain score & $120(17.0)$ & $255(36.1)$ & $282(39.9)$ & $50(7.1)$ \\
\hline
\end{tabular}

Data is presented as number of patients (percentage).

Table VI. Average pain experienced by patients over the 24 hours after surgery, according to the type of surgery ( $\mathrm{n}=\mathbf{7 0 7}$ ).

\begin{tabular}{|c|c|c|c|c|c|}
\hline \multirow{2}{*}{$\begin{array}{l}\text { Anticipated } \\
\text { level of pain }\end{array}$} & \multirow[t]{2}{*}{ Type of surgery } & \multicolumn{4}{|c|}{ Severity of pain [No. (\%)*] } \\
\hline & & None & Mild & Moderate & Severe \\
\hline \multirow[t]{6}{*}{ Mild } & Minor head and neck $(n=53)$ & $12(22.6)$ & $25(47.2)$ & $13(24.5)$ & $3(5.7)$ \\
\hline & Minor upper limb $(n=15)$ & $1(6.7)$ & $6(40.0)$ & $5(33.3)$ & $3(20.0)$ \\
\hline & Minor urological $(n=51)$ & $24(47.1)$ & $16(31.4)$ & $9(17.6)$ & $2(3.9)$ \\
\hline & Minor lower abdomen (non-O\&G) (n=24) & $2(8.3)$ & $11(45.8)$ & $10(41.7)$ & $1(4.2)$ \\
\hline & Minor lower limb $(n=39)$ & $4(10.3)$ & $15(38.5)$ & $17(43.6)$ & $3(7.7)$ \\
\hline & Other $(n=19)$ & $2(10.5)$ & $9(47.4)$ & $5(26.3)$ & $3(15.8)$ \\
\hline \multirow[t]{9}{*}{ Moderate } & Major head and neck ( $n=15)$ & $3(20.0)$ & $3(20.0)$ & $6(40.0)$ & $3(20.0)$ \\
\hline & Intermediate upper limb $(n=30)$ & $3(10.0)$ & $12(40.0)$ & $11(36.7)$ & $4(13.3)$ \\
\hline & Minor thoracic and breast $(n=26)$ & $6(23.1)$ & $14(53.8)$ & $6(23.1)$ & $0(0)$ \\
\hline & Minor upper abdomen $(n=35)$ & $6(17.1)$ & $15(42.9)$ & $13(37.1)$ & $1(2.9)$ \\
\hline & Intermediate lower abdomen (O\&G) $(n=110)$ & $16(14.5)$ & $46(41.8)$ & $45(40.9)$ & $3(2.7)$ \\
\hline & Intermediate lower limb $(n=71)$ & $16(22.5)$ & $24(33.8)$ & $26(36.6)$ & $5(7.0)$ \\
\hline & Minor spine $(n=9)$ & $1(11.1)$ & $2(22.2)$ & $4(44.4)$ & $2(22.2)$ \\
\hline & $>1$ site $(n=7)$ & $0(0)$ & $3(42.9)$ & $4(57.1)$ & $0(0)$ \\
\hline & Others $(n=10)$ & $3(30.0)$ & $2(20.0)$ & $4(40.0)$ & $1(10.0)$ \\
\hline \multirow[t]{7}{*}{ Severe } & Major upper limb $(n=12)$ & $1(8.3)$ & $4(33.3)$ & $7(58.3)$ & $0(0)$ \\
\hline & Major thoracic $(n=16)$ & $2(12.5)$ & $5(31.3)$ & $8(50.0)$ & $1(6.3)$ \\
\hline & Major upper abdomen $(n=17)$ & $2(11.8)$ & $6(35.3)$ & $7(41.2)$ & $2(11.8)$ \\
\hline & Major lower abdomen (non-O\&G) $(n=15)$ & $1(6.7)$ & $0(0)$ & $13(86.7)$ & $1(6.7)$ \\
\hline & Major lower abdomen (O\&G) $(n=1)$ & $0(0)$ & $1(100.0)$ & $0(0)$ & $0(0)$ \\
\hline & Upper and lower abdomen $(n=18)$ & $0(0)$ & $4(22.2)$ & $11(61.1)$ & $3(16.7)$ \\
\hline & $>1$ site $(n=6)$ & $2(33.3)$ & $2(33.3)$ & $1(16.7)$ & $1(16.7)$ \\
\hline
\end{tabular}

*Percentages are calculated based on the number of patients within each type of surgery. O\&G: obstetrics \& gynaecology

postoperative sore throat (odds ratio [OR] 1.79, 95\% $\mathrm{Cl}$ 1.18-2.72) than patients who had laryngeal mask airways.

In the present study, as 28 patients had dementia or other conditions that could cause confusion prior to surgery, CAM-ICU was not administered to them. Of the 679 patients who were well prior to surgery, 155 were aged $>65$ years. Overall, the incidence of postoperative confusion at 24 hours was $1.0 \%(n=7)$. Among the patients aged $>65$ years, the incidence of postoperative confusion at 24 hours was $3.9 \%(n=6)$. The overall incidence of emergence delirium was $0.6 \%(n=4)$.

None of the patients in the present study were documented (in the case notes) to have an altered mental state by any of the ward doctors, nurses or allied health professionals, in the 24 hours after surgery, including the seven patients who were diagnosed using CAM-ICU. Atropine was not used in any of the seven patients who experienced postoperative confusion.

\section{DISCUSSION}

The present study showed a high incidence of PONV and moderate to severe postoperative pain in surgical inpatients. These two factors would have affected the quality of the patients' recovery as well as their perioperative experience. The overall occurrence of PONV in the present study is comparable to the rates that were reported in a meta-analysis of 22 studies ( $\mathrm{n}=95,154)$. $^{(1)}$ In that meta-analysis, a large variation in the incidence of PONV (from 9\% to 56\%) was found. ${ }^{(1)}$ There is much 
Table VII. Pharmacologic analgesic use according to anticipated level of pain.

\begin{tabular}{|c|c|c|c|c|c|c|c|c|}
\hline \multirow{2}{*}{$\begin{array}{l}\text { Anticipated level } \\
\text { of pain }\end{array}$} & \multicolumn{8}{|c|}{ Type of analgesia } \\
\hline & None & Paracetamol & $\begin{array}{l}\text { NSAIDs/ } \\
\text { coxibs }\end{array}$ & $\begin{array}{l}\text { SC/IM/PO } \\
\text { opioid }\end{array}$ & $\begin{array}{l}\text { Continuous } \\
\text { IV infusion/ } \\
\text { PCA opioid }\end{array}$ & $\begin{array}{l}\text { Regional } \\
\text { (LA } \\
\text { infusion) }\end{array}$ & Tramadol & Others \\
\hline \multicolumn{9}{|l|}{ Mild $(n=210)$} \\
\hline Prescribed & $5(2.4)$ & $194(92.4)$ & $97(46.2)$ & $37(17.6)$ & $4(1.9)$ & $3(1.4)$ & $55(26.2)$ & $13(6.2)$ \\
\hline Administered & $22(10.5)$ & 164 (78.1) & $85(40.5)$ & $21(10.0)$ & $4(1.9)$ & $3(1.4)$ & $49(23.3)$ & $4(1.9)$ \\
\hline \multicolumn{9}{|l|}{ Moderate $(n=327)$} \\
\hline Prescribed & $3(0.9)$ & $314(96.0)$ & $204(62.4)$ & $87(26.6)$ & $34(10.4)$ & $14(4.3)$ & $132(40.4)$ & $22(6.7)$ \\
\hline Administered & $12(3.7)$ & 291 (89.0) & $179(54.7)$ & $46(14.1)$ & $34(10.4)$ & $14(4.3)$ & $125(38.2)$ & $7(2.1)$ \\
\hline Adherence* & - & 92.7 & 87.7 & 52.9 & 100.0 & 100.0 & 94.7 & 31.8 \\
\hline \multicolumn{9}{|l|}{ Severe $(n=170)$} \\
\hline Prescribed & $2(1.2)$ & $157(92.4)$ & $92(54.1)$ & $51(30.0)$ & $95(55.9)$ & $14(8.2)$ & $110(64.7)$ & $18(10.6)$ \\
\hline Administered & $4(2.4)$ & $150(88.2)$ & $87(51.2)$ & $13(7.6)$ & $95(55.9)$ & $14(8.2)$ & $98(57.6)$ & $6(3.5)$ \\
\hline \multicolumn{9}{|l|}{ All $(n=707)$} \\
\hline Prescribed & $10(1.4)$ & 665 (94.1) & $393(55.6)$ & $175(24.8)$ & $133(18.8)$ & $31(4.4)$ & $297(42.0)$ & $53(7.5)$ \\
\hline Administered & $38(5.4)$ & $605(85.6)$ & $351(49.6)$ & $80(11.3)$ & $133(18.8)$ & $31(4.4)$ & $272(38.5)$ & $17(2.4)$ \\
\hline Adherence* & - & 91.0 & 89.3 & 45.7 & 100.0 & 100.0 & 91.6 & 32.1 \\
\hline
\end{tabular}

Data is presented as number of patients (percentage). *Adherence refers to the percentage of prescriptions that were adhered to. This was calculated using the ratio of the number of patients who received the analgesic to the number of patients who were prescribed that analgesic. Coxibs: selective COX-2 inhibitors; IM: intramuscular; IV: intravenous; LA: local anaesthesia; NSAIDs: nonsteroidal anti-inflammatory drugs; PCA: patient-controlled analgesia; PO: oral route; SC: subcutaneous

Table VIII. Incidence of postoperative sore throat.

\begin{tabular}{lccr}
\hline Variable & \multicolumn{3}{c}{ No. of patients (\%) } \\
\cline { 2 - 4 } & $\begin{array}{c}\text { Sore } \\
\text { throat }\end{array}$ & $\begin{array}{c}\text { No sore } \\
\text { throat }\end{array}$ & Total \\
\hline Tracheal intubation & $86(25.5)$ & $251(74.5)$ & $337(100.0)$ \\
Laryngeal mask airway & $40(16.1)$ & $209(83.9)$ & $249(100.0)$ \\
Face mask & $0(0)$ & $4(100.0)$ & $4(100.0)$ \\
i-gel airway & $1(11.1)$ & $8(88.9)$ & $9(100.0)$ \\
Total & $127(21.2)$ & $472(78.8)$ & $599(100.0)$ \\
\hline
\end{tabular}

room for improvement in the effort to reduce the proportion of patients who experience PONV.

In the present study, it was of concern that a small proportion of patients reported severe nausea and frequent vomiting ( $\geq 7$ times), despite receiving antiemetic prophylaxis and treatment. In a study by Apfel et al, in which the Apfel scoring system was used, the authors reported PONV rates of $10 \%, 21 \%$, $39 \%, 61 \%$ and $78 \%$ for the Apfel scores of $0,1,2,3$, and 4 , respectively. ${ }^{(6)}$ In comparison, there was a higher occurrence of PONV in the patients with lower Apfel scores (i.e. 0 and 1) and a lower occurrence of PONV in those with higher Apfel scores (i.e. 2, 3 and 4) in the present study (Table III). The Apfel score risk factors (i.e. female gender, history of PONV/motion sickness, nonsmoking status and postoperative opioid analgesia) were all found to be significant risk factors in the present study; there was a clear trend of increasing incidence of PONV with increasing Apfel score among our patients. This suggests that the score may be useful to guide risk stratified antiemetic prophylaxis. As the frequency of the use of TIVA and nitrous oxide were low in the present study, we were not able to evaluate their impact on PONV in our patients. The use of nitrous oxide is very low in our hospital as there are concerns regarding its adverse effects on PONV, closed gas spaces and neurophysiological monitoring.
A large proportion of the patients in the present study had moderate to severe pain within the first 24 hours after surgery. This was despite routine multimodal analgesic use in the patients in whom moderate to severe postoperative pain was anticipated. The prescription of opioids in patients in whom moderate pain was anticipated was low and the actual administration was even lower. Prescriptions of subcutaneous, intramuscular and oral opioids were adhered to only $45.7 \%$ of the time despite the high pain scores. In our hospital, PCA is mainly used when severe pain is anticipated. In the present study, $18.8 \%$ of the patients were prescribed and administered PCA. This usage is similar to that of other studies..$^{(9)}$

In the present study, the patients' experience of moderate to severe pain is similar to that of other studies. ${ }^{(2,7,10)}$ In addition, we found that non-opioid analgesics were most commonly used in the present study (Table VII) $-94.1 \%$ of the patients were prescribed paracetamol and 55.6\% were prescribed NSAIDs/coxibs. Only $24.8 \%$ were prescribed subcutaneous, intramuscular or oral opioids and $18.8 \%$ were prescribed intravenous infusion or PCA opioids. Opioids were prescribed mainly for patients who were expected to experience severe pain. Other than PCA morphine, intramuscular pethidine was the next most commonly prescribed opioid; it was prescribed on an as-required basis. The low adherence to opioid prescription could be due to a few reasons: (a) healthcare providers may have been reluctant to administer intramuscular opioids due to concerns regarding their side effects, such as opioid-induced respiratory depression; (b) patients may have been unaware that they could ask for more analgesia; and/or (c) healthcare providers may not have assessed patients' pain frequently enough. Regular opioid administration and better adherence to opioid prescriptions may improve postoperative pain scores. Although oxycodone was not used for postoperative analgesia in our hospital at the time of the present study, oxycodone and other oral opioids may enable 
easier opioid administration, and thus, improve adherence to opioid prescriptions.

The Acute Pain Service in our hospital manages patients who are prescribed PCA morphine and regional analgesia infusions. Generally, patients who have undergone extensive and complex surgery are prescribed such analgesics. In the present study, $2.0 \%$ of these patients had severe pain at rest and $25.5 \%$ had severe pain with movement. This suggests that there could be a limit to the effectiveness of PCA morphine.

The results of the present study also suggest that it is difficult to accurately predict the extent of pain that the patients will experience and that it is common to underestimate the extent of the pain that will be experienced. Most patients who underwent surgeries that were predicted to result in mild postoperative pain were not prescribed opioids. Examples of such surgeries include minor gynaecological operations, upper limb peripheral vascular surgery, wound debridement and inguinal hernia repairs, where contrary to prediction, a substantial proportion are known to experience moderate or even severe postoperative pain. This was reported in a recent multicentre study. ${ }^{(11)}$

The methodology employed in the present study has inherent limitations. The use of data obtained from a single interview for a 24-hour period is limited by recall bias. However, as the documentation of pain assessment in routine clinical charts would have been done by several different nurses for each patient, it would be difficult to ensure that the assessments were done in a consistent manner for all the patients. While future studies could include the use of a trained assessor to obtain data contemporaneously, this was not feasible in the present study.

In the present study, multimodal or balanced analgesia was consistently used for patients who had undergone major surgeries in which severe postoperative pain was anticipated. Despite this, acute postoperative pain management was not optimal. Therefore, regular opioid prescription and administration may be needed to improve pain management. Procedure-specific postoperative pain management guidelines, regular staff training on postoperative pain management, and systematic information and education for the patient before surgery may improve postoperative pain management. ${ }^{(12)}$

Postoperative sore throat was found to be common with tracheal intubation and supraglottic airways in the present study. As such, we recommend that patients be informed of this risk preoperatively. While there were only four surgical inpatients whose anaesthesia involved the use of a facemask (i.e. tracheal tubes or supraglottic airways were not used), none of these patients experienced postoperative sore throat.

Postoperative confusion has mainly been studied in geriatric patients. Its reported incidence varies widely between $0 \%$ and $75.3 \%{ }^{(13)}$ a review of 80 studies estimated the incidence to be about $38.6 \% .{ }^{(13)}$ This wide variation reflects differences in: (a) the diagnostic criteria for delirium; (b) the population studied; and (c) the method of postoperative surveillance for delirium. ${ }^{(13)}$ In the present study, using CAM-ICU, we found that the incidence of postoperative confusion in patients aged $\geq 65$ years was
$3.9 \%$. Interestingly, none of the patients who were found to have postoperative confusion using CAM-ICU were documented to have confusion in the ward. This suggests that screening tools such as CAM-ICU can be a more sensitive measure of postoperative confusion. The incidence of postoperative confusion in the present study is comparable to that of another study that also used CAM-ICU (the incidence of postoperative confusion in the latter study was $7.6 \%)$. ${ }^{(8)}$ Removal of precipitating factors, as well as treatment, is required to prevent persistent and worsening confusion. ${ }^{(14)}$

In summary, the present study identified factors that increased the risk of PONV in a local patient population. Apfel risk scores were found to be associated with the risk of PONV; a significant trend of increasing PONV was observed with higher Apfel scores. Multimodal treatment, which is commonly used for postoperative pain management, was found to be insufficient. We also found that non-opioid analgesics were most commonly used for postoperative pain management. It is difficult to predict the extent of postoperative pain, and patients having minor surgery may have moderate or even severe pain. The CAM-ICU screening tool showed a low incidence of postoperative confusion in our study population.

\section{REFERENCES}

1. Apfel CC, Heidrich FM, Jukar-Rao S, et al. Evidence-based analysis of risk factors for postoperative nausea and vomiting. Br J Anaesth 2012; 109:742-53.

2. Dolin SJ, Cashman JN, Bland JM. Effectiveness of acute postoperative pain management: I. Evidence from published data. Br J Anaesth 2002; 89:409-23.

3. Macario A, Weinger M, Carney S, Kim A. Which clinical anesthesia outcomes are important to avoid? The perspective of patients. Anesth Analg 1999; 89:652-8.

4. Vaurio LE, Sands LP, Wang Y, Mullen EA, Leung JM. Postoperative delirium: the importance of pain and pain management. Anesth Analg. 2006; 102:1267-73.

5. Leung JM, Sands LP, Lim E, Tsai TL, Kinjo S. Does preoperative risk for delirium moderate the effects of postoperative pain and opiate use on postoperative delirium? Am J Geriatr Psychiatry 2013; 21:946-56.

6. Apfel CC, Läärä E, Koivuranta M, Greim CA, Roewer N. A simplified risk score for predicting postoperative nausea and vomiting: conclusions from cross-validations between two centers. Anesthesiology 1999; 91:693-700.

7. Sommer M, de Rijke JM, van Kleef M, et al. The prevalence of postoperative pain in a sample of 1490 surgical inpatients. Eur J Anaesthesiol 2008; 25:267-74.

8. Friedman Z, Qin J, Berkenstadt H, Katznelson R. The confusion assessment method--a tool for delirium detection by the acute pain service. Pain Pract 2008; 8:413-6.

9. Fletcher D, Fermanian C, Mardaye A, Aegerter P. A patient-based national survey on postoperative pain management in France reveals significant achievements and persistent challenges. Pain 2008; 137:441-51.

10. Apfelbaum JL, Chen C, Mehta SS, Gan TJ. Postoperative pain experience: results from a national survey suggest postoperative pain continues to be undermanaged. Anesth Analg 2003; 97:534-40.

11. Gerbershagen HJ, Aduckathil S, van Wijck AJ, et al. Pain intensity on the first day after surgery: a prospective cohort study comparing 179 surgical procedures. Anesthesiology 2013; 118:934-44.

12. Benhamou D, Berti M, Brodner G, et al. Postoperative Analgesic THerapy Observational Survey (PATHOS): a practice pattern study in 7 central/ southern European countries. Pain 2008; 136:134-41.

13. McDaniel M, Brudney C. Postoperative delirium: etiology and management. Curr Opin Crit Care 2012; 18:372-6.

14. Chaput AJ, Bryson GL. [Postoperative delirium: risk factors and management: continuing professional development]. Can J Anaesth 2012; 59:304-20. English, French. 


\title{
Annex
}

\author{
AT 24-HOUR IN THE WARD \\ Postoperative nausea and vomiting \\ 1. Have you experienced any nausea since your operation?
$\square$ Yes
$\square$ No \\ 2. (If Yes to Q1) How would you rate the severity of nausea?
$\square$ Mild
$\square$ Moderate
$\square$ Severe

3. Have you experienced any vomiting since your operation?
$\square$ Yes
$\square$ No

4. (If Yes to Q3) On how many occasions have you vomited since your operation?
$\square 1$
$\square 2$
$\square 3$
$\square 5$
$\square 6$
$\square>7$

Postoperative pain

1. How is your pain at rest now?
$\square$ Mild
$\square$ Moderate
Severe

2. How is your pain with movement now?
$\square$ Mild
$\square$ Moderate
Severe

3. What is your worst pain over the last 24 hours?
$\square$ Mild
$\square$ Moderate
$\square$ Severe

4. What is your least pain over the last 24 hours?
$\square$ Mild
$\square$ Moderate
Severe

5. How is your average pain over the last 24 hours?
$\square$ Mild
$\square$ Moderate
$\square$ Severe

6. Do you have a sore throat?
$\square$ Yes
$\square$ No

Postoperative confusion (adapted from the Confusion Assessment Method)

(A) Acute onset and fluctuating course

1. Any acute change in mental status from the patient's baseline? (Assessed by interviewer with reference to pre-op clinical charts)

$\square$ Yes

$\square$ No

(B) Inattention (assessed by interviewer)

1. Difficulty focusing attention?

$\square$ Yes

$\square$ No

2. (If present or abnormal) Did this behaviour fluctuate during the interview? (That is, tend to come and go or increase and decrease in severity)
$\square$ Yes
$\square$ No
$\square$ Not applicable

(C) Disorganised thinking

1. Thinking disorganised or incoherent? (Yes if incorrect answers to $\geq 2$ of the following 4 'Yes/ $\mathrm{No}^{\prime}$ questions)

$\square$ Will a stone float on water?

$\square$ Are there fish in the sea?

$\square$ Does $1 \mathrm{~kg}$ weigh more than $2 \mathrm{~kg}$ ?

$\square$ Can you use a hammer to pound a nail?

(D) Altered level of consciousness

1. What is the patient's level of consciousness? (Assessed by interviewer)

$\square$ Alert (normal)

$\square$ Vigilant (hyper-alert)

$\square$ Lethargic (drowsy but easily roused)

$\square$ Stuporous (difficult to rouse)

$\square$ Comatose (unrousable) 